\title{
Aprehender el movimiento, no congelar un instante
}

por

ALBERTO DALLAL

\author{
\$ \\ G uillermina Bravo. I conografía \\ investigación iconográfica y documental \\ de Patricia Cardona \\ M éxico, Instituto $\mathrm{N}$ acional de Bellas Artes-C onsejo \\ $\mathrm{N}$ acional para la Cultura y las Artes, 1996, I65 P.
}

U na frase que Susan Sontag aplica a la fotografía en general podría adjudicarse, sin menoscabo de elementos y con plena intensidad, a la fotografía de danza: "A la fotografía se le maneja como forma del conocimiento sin el conocimiento: no es una manera de lanzarle un ataque frontal al mundo sino de deslumbrarlo" (Susan Sontag, "La fotografía como un fin en sí mismo", en Revista de la U niversidad de M éxico, vol. xxxi, núm. 9, de mayo de i977).

En efecto, la fotografía de danza va más allá de la intelectualización acerca de la imagen que proviene del objeto-objetivo; además trasciende y supera el problema que surge en torno de la posibilidad de que el fotógrafo (creador) practique la reflexión en el momento de la "toma". Se entiende que por destacar entre sus objetivos ineludibles el movimiento mismo, la fotografía de danza deja muy atrás el tema de la "singularización" del tiempo mediante los procedimientos aplicados por la técnica fotográfica.
El "instante helado" en danza se convierte en movimiento intensificado, pues el observador "lee", completa el movimiento que la figura de la foto expresa. La existencia y el desarrollo de la fotografía de danza obliga incluso a situar en el pasado aquellas ideas magníficamente expuestas por W alter Benjamin (D iscursos interrumpidos, M adrid, T aurus, 1973) acerca del valor cultural de la fotografía; un pasado, sí, lleno de imágenes, daguerrotipos y vivencias decimonónicas, mas un pasado superado. Por último, el hecho de que para el fotógrafo de danza el objeto-objetivo se encuentre en movimiento, en plena actividad - se localice en su propio dinamismo-, corrobora la tesis según la cual la fotografía representaría la "mirada subjetiva" por antonomasia: un producto artístico que corresponde, no al "instante helado" o al "detalle captado", sino precisamente a una realidad inventada o subjetivada al máximo. (La idea de contraponer la acción subjetivadora de la fotografía a la objetivadora del cine está expuesta brevemente en Alberto D allal, "Espacios, texturas y alquimias de Rafael Doniz", en D iálogos [M éxico], vol. I3, núm. I [73], enero-febrero de 1977, p. I.)

El número reducido de fotógrafos hábiles para crear impresiones de danza comprueba que el fenómeno "fotografía de danza" es un desafío. En cierta medida constituye un extremo de la actividad foto- 
DOI: http://dx.doi.org/10.22201/iie.18703062e.1997.70.1783

gráfica: intervienen luces, unidades móviles, cambios de expresión corporal, intensa afloración de imágenes sucesivas, de imágenes que se ofrecen "por secuencias". Además, la enorme variedad de las "danzas" que existen desde tiempos ancestrales $-\mathrm{y}$ la diversificación, asentamiento y beligerancia histórica de sus géneros- ha obligado al fotógrafo a introducirse, a veces infructuosamente, en un mundo vasto y complejo. Aquellos elementos que para el observador resultan bondades de un arte (sea éste fotografía o danza), para el fotógrafo constituyen verdaderas fieras que deben ser domadas. No sólo los fotógrafos "especialistas" en danza son peleados y se hallan debidamente cotizados sino que cualquier fotógrafo profesional, cualquier creador de la fotografía, considera a la danza como un campo en el que culminan su experiencia, sus conocimientos, la aplicación de su 0 sus técnicas. Para penetrar en él se ve obligado a "especializar" sus funciones y aptitudes. $Y$ ya que no es posible negar la representatividad de las fotos de danzas antiguas (conocemos a N ijinsky, Isadora, Wigman, Ruth St. Denis en plena acción), en cambio sí puede aducirse que muy poco de estas fotos, placas, imágenes, puede considerarse creativo en el sentido cabal del término, o sea: la gran mayoría de estas fotos atraen por sus valores documentales y no por sus valores estéticos. Aún más: los efectos que logran incorporar muchas fotografías (ila gran mayoría?) de grupos de danza en acción resultan sumamente atractivos pero no coinciden con ciertas inexistentes cualidades estéticas de las coreografías. Si acaso, nos permiten deducir un momento brillante; son una interpretación (fotográfica) de la interpretación (coreográfica). Con todo, en la época contemporánea han surgido fotógrafos que plasman en sus placas e impresiones la expresividad, no sólo de la ejecución, sino también las características particulares de la fotografía y - lo que es más sorprendente todavía- las más amplias cualidades del género dancístico al que penetran sus miradas. El énfasis que se otorga actualmente a la publicidad ha agudizado, por una parte, la necesidad de hacer más aptas las facultades y funciones de la fotografía de danza y, por la otra, la necesidad de deslindar los objetivos y logros entre la fotografía de danza (un arte en sí mismo) y la fotografía publicitaria. De existir, puede ser detectada ahora por los ojos de experimentados lectores, al guna desarmonía o falta de conciencia y coincidencia entre la calidad fotográfica (méritos comprobables si se analizan aisladamente de su función publicitaria) y las características propias de las obras, personajes y coreografías captadas.

Esta serie de rasgos de la fotografía de danza nos hace dudar de la mayor parte de los fotógrafos que buscan $-y$ tal vez encuentran - objetivos dancísticos. El hecho de que a una buena, lograda fotografía (en ocasiones a una excepcional, excelente fotografía) corresponda una danza y/o un bailarín o bailarina mediocres, nos hace cautos al respecto. Por una parte, el fenómeno expresa de nueva cuenta la cualidad "subjetivadora" de la fotografía; por la otra, constituye una llamada de atención para el crítico o el teórico de la danza, respecto de la necesidad de buscar en el lenguaje dancístico, no en la expresión dancística, las cualidades últimas y fundamentales del arte de la danza, un arte cuyo conocimiento no se puede apreciar exclusivamente por conductos fotográficos (véanse las diferencias y contraposiciones entre lenguaje y expresión dancística en Alberto D allal, "D anza como lenguaje, 
danza como expresión: al gunas consideraciones teóricas", en La danza contra la muerte, M éxico, Universidad N acional Autónoma de M éxico-Instituto de Investigaciones Estéticas, 1993, pp. 41-56). M ás aún: una buena fotografía de danza contiene valores que le son propios y expresan su propia esté tica a los ojos del observador. Sin embargo, a la luz de la funcionalidad propia de la fotografía, si esta foto hace "bella" u operativa o "buena" esa danza cuya imagen ha captado, estará remitiendo al observador (al crítico, al teórico) a un juego realidad-irrealidad que requerirá de parámetros analíticos especiales para evaluar la operatividad y la estética de la fotografía tomada.

En este punto parece surgir una paradoja. Si insistimos (como lo hemos hecho) en considerar a la fotografía como la intensificación de la mirada y si resolvemos que su acción subjetivadora es directamente proporcional a la concentración del observadorfotógrafo sobre su objeto-objetivo, entonces el cinematógrafo (mirada móvil, tiempo prolongado, secuencias sucesivas) permitirá una "mirada" más "objetiva", más cercana a la captación de la realidad real de una obra o de una "escena". (La forma contemporánea más funcional de registrar la danza sigue siendo el cine y tal vez represente la mejor - ila única?- posibilidad de notación dancística. Nítidos y manipulables registros de cine, en este sentido, superan incluso al sistema de videotape, tan en boga hoy en día en los grupos de danza.) En el caso de la danza, esta situación (fotografía: subjetivización; cine: objetivización) se hace más evidente: las imágenes del cine permiten que, tras el seguimiento visual de una secuencia, el observador sepa cabalmente si la coreografía es buena o mala, completa o incompleta, así o asado; si la interpretación del o de los bailarines idem, etcétera. Por el contrario, una foto de esa danza sólo esbozará algunas de las características generales de la danza y del bailarín y sólo en un caso extremo de calidad y "perspicacia fotográfica" integrará en su capacidad de expresión las características todas de la coreografía y de la interpretación. Por tanto, estaremos ante un fenómeno peculiar: el grado de subjetivación que impone la fotografía, por su misma naturaleza, se agudizará ante un objeto-objetivo que ofrece dificultades especiales a causa de sus propias emisiones de subjetividad y en términos de su propia naturaleza dinámica.

D ebido al movimiento que le es propio, la danza no puede guardar con la fotografía las mismas relaciones (objetivas y/o subjetivas) que guarda con el cine. En el ámbito de las actividades fotográficas, el fenómeno que ofrece la danza sólo es comparable a la fotografía documental y periodística, aquella que surge y se ocupa de sucesos 0 acontecimientos violentos, dinámicos, "informativos", etcétera. Y todo el mundo conoce la enorme cantidad de elementos propagandísticos, suscitadores, demagógicos o distorsionadores (subjetivos) aplicables a este género de fotografía. (En muchos reportajes periodísticos se hace hincapié en elementos que subrayan un sentido particular.) 0 bien la posibilidad de alejamiento de la realidad real (en este caso el número de danza) subidos en el vehículo de una fotografía que "distorsiona" la acción o que impone elementos distorsionadores según la voluntad del fotógrafo (luminosos, de claroscuro, de tratamiento en laboratorios, de acercamiento). D e esta manera, el fotógrafo bien puede "deslumbrar" porque su producto es algo más que un "ataque frontal al mundo" pero muy bien puede estar "inventando" volun- 
DOI: http://dx.doi.org/10.22201/iie.18703062e.1997.70.1783

taria o involuntariamente esa parte del mundo que ha captado, en su caso exagerando las cualidades, las habilidades, las características del género dancístico, de la tendencia, de la obra o de las aptitudes físicas 0 artísticas del bailarín 0 bailarina. Para evitar esta verdadera distorsión, el fotógrafo de danza deberá ser a la vez un conocedor de la dinámica dancística, de las peculiaridades de la obra y los intérpretes; deberá percibir algo de la historia y de la dinámica de ese arte y de sus géneros, así como de la naturaleza de las obras que él contempla. En una palabra, deberá dejarse deslumbrar por el conocimiento de la danza antes que deslumbrarnos con sus fotografías. En cierta forma, el fotógrafo deberá familiarizarse con el ambiente, la atmósfera de la danza y trabajar en varias o durante muchas sesiones con los coreógrafos, maestros y bailarines de la danza.

A partir de los años sesenta, el advenimiento - verdadero estallido - del género contemporáneo en el arte de la danza permitió la incorporación a los trabajos de los coreógrafos de un vasto grupo de artistas plásticos y de fotógrafos. Estos últimos al fin penetraron en un mundo - la fotografía de danza- que se había configurado anteriormente con excepciones, entre ellas la de Barbara M organ, "decana" de trabajos fotográficos especializados como el que realizó con M artha Graham (Barbara M organ, M artha Graham. Sixteen Dances in Photographs, N ueva York, D uell, Sloan and Pearce, 194r). En M éxico, el deslumbrante movimiento de danza moderna - equívocamente denominado "época de oro" puesto que jamás permaneció aislado ni manifestó rupturas sino extinciones- hizo que se adhirieran fotógrafos excepcionales y profundamente acuciosos como Walter Reuter, N acho López y
Rodrigo M oya, pero entre 1939 y 1960, periodo de gran actividad dancística en M éxico, no aparecen libros especialmente diseñados y realizados para "mostrar" con fotografías los innumerables trabajos coreográficos del periodo. La ausencia de revistas especializadas obliga a los fotógrafos intere sados en el tema a acompañar con sus trabajos e impresiones las notas, reseñas, crónicas y reportajes que el reducido número de críticos de danza publica en periódicos y revistas culturales.

La reciente aparición de un libro que da a conocer la iconografía biográfica y profesional de Guillermina Bravo permite corroborar una porción de los razonamientos anteriores. D e gran formato, las fotos de esta publicación devienen en interesantes miradas, heladas y en ocasiones intensas $-y$ a veces ingenuas y tiernas- de la trayectoria de Bravo que, por ende, constituyen una porción importante de la trayectoria de la danza contemporánea en M éxico. Las imágenes reproducidas son registros visuales que desentrañan, revelan, a veces a pesar de las intenciones del fotógrafo, ciertas significaciones depositadas en los rostros, en los cuerpos, los sucesos, los espacios del mundo y de la danza mexicana y de sus elementos. En este libro, titulado Guillermina Bravo. I conografía, un conjunto de talentosos fotógrafos y también de fotógrafos aficionados y de fotógrafos ocasionales nos revela, en principio, sectores de la vida y obra de esa creadora y organizadora, vital y amenazante a veces, tierna y productiva otras, que en M éxico hizo transitar a la danza moderna en dirección de la danza contemporánea; que satisfizo, con creces, las necesidades de un país de danzantes en un momento histórico específico, y que, además, sentó las bases para la prolongación, esperamos que 
DOI: http://dx.doi.org/10.22201/iie.18703062e.1997.70.1783

APREHENDER EL MOVIMIENTO

ad infinitum, de la creatividad dancística y coreográfica de la nación. La publicación del libro cerró acertadamente un año completo - noviembre de i995-noviembre de I996 - de homenajes a la bailarina, maestra y coreógrafa en celebración de sus 75 años de edad. El libro fue limpiamente diseñado por Bernardo Recamier.

Siempre me he preguntado cuáles fueron las excepcionales circunstancias que hicieron converger en G uillermina esa enorme capacidad, o más bien, esa summa de impulsos y capacidades que la erigieron en paradigma de su arte y de su comunidad de artistas. Vivacidad, inteligencia, proyecto y acción, certeza y prurito de cambio, de superación, de asentamiento razonado y razonable. M odelo de constancia, de tenacidad, con sus variantes de rebeldía, de oposición, de revolucionarismo. ¿Circunstancias sociales, acontecimientos, accidentes, casualidades? ¿Eslabón genético, martirio, autotransformación, razonamiento, análisis? Todo contribuyó para forjarla, pero también intuición, instinto, invento y -10 sabemos tardíamente- fascinación y magia. Ya en I926, la mirada de la "escuinclita" pone en entredicho las capacidades de registro de la cámara o probablemente del fotógrafo. En la foto de grupo de 1936, en el Conservatorio de M úsica, no es necesaria la acotación que nos indica la ubicación central de Guillermina: su mirada revela que se trata de un personaje solitario, que mira más allá del espacio y del tiempo y que, a lo Bette $D$ avis, revela intensidades y obsesiones que tal vez sobrecogen a sus congéneres pero que evidentemente sobrevuelan por ese ámbito cultural particular y nacional que presiente $-\mathrm{y}$ necesita - los cambios que en seguida se dejarán venir en todo el mundo.

En las fotos que corresponden a la bai- larina, sus grupos, las obras del movimiento de danza moderna, descubrimos a un rostro y a un cuerpo condescendientes, en los que la expresividad se corresponde, como lo exigía la danza de esa época, con cuerpos ávidos de superar delicadezas y movimientos y objetivos "finos" o superficiales. Es la GuiIlermina, ahora sí, enérgica y energética, que se ha salido de ese ámbito familiar y social pero que, guardando vínculos con él, se siente todavía anclada a un lenguaje dancístico insuficiente. Resulta curiosa su firme naturalidad en las fotos inmediatamente posteriores, las del viaje a Asia y a Europa, en 1957, cuando, según ella misma ha explicado, descubrió la necesidad de que en M éxico el bailarín y el coreógrafo se concentraran en cuerpo y alma, se sumergieran en la danza, se lanzaran enteros a las profundidades de la preparación y de la técnica, al destino de un lenguaje dancístico concre to y consciente, y apostaran por la profesionalización (véase D allal, La danza contra la muerte, p. 124).

$M$ ás que un estilo propio, Guillermina Bravo crea un universo propio. N o sólo perfecciona y asienta el modelo, la estructura adecuada para salvaguardar el arte de la danza: una compañía apoyada en el subsidio gubernamental - obligación del Estado para con los artistas- pero dueña por completo de su libertad creativa, de su independencia técnica, de sus procesos de búsqueda y maduración. Entre esas fotos-documentos de los grandes, Walter Reuter y $\mathrm{N}$ acho López, y las versátiles y penetrantes, aladas, a veces embelesadas fotos de Christa Cowrie, M aritza López, Rafael D oniz y otros más jóvenes, parece existir un hueco, un silencio visual. Son los últimos sesentas y los primeros setentas, años de surgimiento de la danza contemporánea - a la que todavía 
DOI: http://dx.doi.org/10.22201/iie.18703062e.1997.70.1783

ahora llamamos, tal vez con inexactitud danza contemporánea- . Es época de avatares y effuerzos, de públicos que redescubren poco a poco, con sorpresa ante lo excepcional y lo inmediato, la vocación dancística enorme y profunda del mexicano. El Ballet $\mathrm{N}$ acional es muestra clara, en ese momento, de sensatez técnica, concentración y entrega profesionales. Simultáneamente hay búsqueda y hay capacitación. La compañía se alimenta de bailarines radicales y estudiosos, hábiles y con disposición al arte de la danza. La Guillermina de esa épo-ca es una artista discutidora y valiente, leal con los que como ella - sienten en carne propia, en cuerpo propio, el forjamiento de un nuevo lenguaje dancístico, de una nueva cultura del cuerpo - que continúa, por cierto, esa gran revolución sensual y sexual de la segunda mitad de los años sesenta- y que harán creer, y acabarán por convencer, de nueva cuenta, a los pocos críticos y a los reducidos públicos, en la danza mexicana. EI Ballet $\mathrm{N}$ acional es el semillero, el centro, el eje, la fuerza centrípeta (véase Alberto $D$ aIlal, "O riginalidad, asimilación y capacidad de síntesis en las técnicas dancísticas. El caso del Ballet $\mathrm{N}$ acional de M éxico", en Encuentros y desencuentros en las artes. XIV Coloquio Internacional de Historia del Arte, M éxico, Universidad $\mathrm{N}$ acional Autónoma de $\mathrm{M}$ éxico-Instituto de Investigaciones Estéticas, 1994, pp. 33-50).

En la primera parte de la sección denominada "El trabajo de cada día" contemplamos grandes momentos de la danza mexicana; intérpretes, obras e instantes en los que ese universo se expresa, se abre, se expande hacia lo que hoy, regocijados, con reconocimiento, vemos en el escenario. La estructura misma del libro - acertadamente establecida por Patricia Cardona- expresa puntual- mente a Guillermina Bravo. Su universo es ella, Guillermina, sus bailarines - sus hermanos- , sus obras, sus espacios. Su estudio de la calle del 57 y su Centro $\mathrm{N}$ acional de $D$ anza Contemporánea en Q uerétaro. Sus colegas coreógrafos. Los artistas e intelectuales que se adhieren o se acercan a un núcleo de gran actividad artística. Guillermina está, en algunas fotos, concentrada en sí misma, vuelta hacia su sabiduría - pienso, sobre todo, en los estudios de M aritza López, verdaderas persecuciones del alma inasible, invisible de Guillermina- ; en otras, su figura se halla revertida hacia lo externo, hacia el espacio. Ella quiere trascender, expresarlo todo, organizarlo todo hacia fuera. Su aura no la rodea, no la corona o la ciñe sino se esparce. Por eso al ver algunas fotos de Rossana Filomarino o de Antonia Q uiroz o de Raúl Almeida o de 0 rlando Scheker o de Victoria Camero, vemos implícitamente a Guillermina Bravo: un estilo de vida, un ambiente fecundado, una obse sión de hacer y de obligar a ser al artista mexicano. Los fotógrafos han captado muy bien, conteniendo el aliento, diría yo, cómo estos bailarines han convertido el vacío en espacio, cómo le han dado nombre, título, cultura, arte. Pero allí, en esos cuerpos desatados, firmes en las formas, está también Guillermina, ese universo definido por ella y sus maestros y sus coreógrafos. Hay que escudriñar en las fotos ciertos momentos de Bastón de mando, ciertos saltos de LeonaCazador, ciertos gritos o exclamaciones corporales de La vida genera danza, M ujeres, Danza para empezar - obras de Guillermina y de sus coreógrafos- para percibir la mirada de la brava Bravo, su sentido de la danza, sus exigentes explicaciones de lo que es la vida, la libertad, la creación, el destino... Es éste un libro excelente gracias a su 
DOI: http://dx.doi.org/10.22201/iie.18703062e.1997.70.1783

APREHENDER EL MOVIMIENTO

factura, a sus fotógrafos y a su registro del mos, ya, denominar el "efecto Guillermina fenómeno histórico y artístico que podeBravo" en la cultura de M éxico. 